\title{
Assessment of sarcopenia as a predictor of poor overall survival for advanced non-small-cell lung cancer patients receiving salvage anti-PD-1 immunotherapy
}

\author{
Yixing Wang ${ }^{1,2,3 \#}$, Ping Chen ${ }^{1,2,4 \#}$, Jinsheng Huang ${ }^{5 \#}$, Minghui Liu ${ }^{1,2,4 \#}$, Dingsheng Peng ${ }^{1,2,6}$, Zichun Li ${ }^{1,2,4}$, \\ Tao Chen ${ }^{1,2,7}$, Shaodong Hong ${ }^{1,2,3}$, Yixin Zhou ${ }^{1,2,4}$
}

${ }^{1}$ State Key Laboratory of Oncology in South China, Guangzhou, China; ${ }^{2}$ Collaborative Innovation Center for Cancer Medicine, Guangzhou, China; ${ }^{3}$ Department of Medical Oncology, Sun Yat-sen University Cancer Center, Guangzhou, China; ${ }^{4}$ Department of VIP Region, Sun Yat-sen University Cancer Center, Guangzhou, China; ${ }^{5}$ The First School of Clinical Medicine, Guangzhou University of Chinese Medicine, Guangzhou, China; ${ }^{6}$ Department of Radiotherapy, Sun Yat-sen University Cancer Center, Guangzhou, China; ${ }^{7}$ Department of Nuclear Medicine, Sun Yat-sen University Cancer Center, Guangzhou, China

Contributions: (I) Conception and design: Y Zhou; (II) Administrative support: T Chen, S Hong, Y Zhou; (III) Provision of study materials or patients: Y Wang; (IV) Collection and assembly of data: Ping Chen, J Huang, M Liu; (V) Data analysis and interpretation: Y Wang, P Chen, J Huang, M Liu; (VI) Manuscript writing: All authors; (VII) Final approval of manuscript: All authors.

\#These authors contributed equally to this work.

Correspondence to: Tao Chen, MD. Department of Nuclear Medicine, Sun Yat-sen University Cancer Center, 651 Dongfeng East Road, Guangzhou 510060, China. Email: chentao@sysucc.org.cn; Shaodong Hong, MD. Department of Medical Oncology, Sun Yat-sen University Cancer Center, 651 Dongfeng East Road, Guangzhou 510060, China. Email: hongshd@sysucc.org.cn; Yixin Zhou, MD. Department of VIP Region, Sun Yat-sen University Cancer Center, 651 Dongfeng East Road, Guangzhou 510060, China. Email: zhouyx@sysucc.org.cn.

Background: Sarcopenia, which is defined as the loss of skeletal muscle mass, has been identified as a poor prognostic factor for cancer patients. This study sought to elucidate the effects of sarcopenia on the outcomes of advanced non-small cell lung cancer (NSCLC) patients receiving salvage anti-programmed death-1 (PD-1) immunotherapy.

Methods: In total, 105 NSCLC patients receiving second-line anti-PD-1 immunotherapy at the Sun Yat-sen University Cancer Center between January 2015 and December 2017 were enrolled in this study, and detailed patient data were collected. Available lumbar computed tomography images of the patients were analyzed to determine the total skeletal muscle cross-section area. The efficacy of the predictive and prognostic role of sarcopenia in progression-free survival (PFS) and overall survival (OS) was analyzed using the Kaplan-Meier method, and the risk factors were analyzed using Cox analyses.

Results: We found that patients with sarcopenia receiving salvage anti-PD-1 immunotherapy had significantly worse PFS (2.67 vs. 7.96 months; $\mathrm{P}<0.001)$ and $\mathrm{OS}(9.08$ vs. 21.84 months; $\mathrm{P}<0.001)$ than their non-sarcopenic counterparts. We also found that sarcopenia was associated with the neutrophil-tolymphocyte ratio (NLR) ( $\mathrm{P}=0.041)$, and that the NLR acts as a predictor of OS.

Conclusions: Sarcopenia was associated with a poor prognosis in advanced NSCLC patients receiving salvage anti-PD-1 immunotherapy. Further research needs to be conducted to identify more biomarkers and the patients most likely to benefit from immunotherapy.

Keywords: Annti-PD-1 immunotherapy; sarcopenia; advanced non-small cell lung cancer (advanced NSCLC)

Submitted Oct 19, 2021. Accepted for publication Dec 17, 2021.

doi: 10.21037/atm-21-6578

View this article at: https://dx.doi.org/10.21037/atm-21-6578 


\section{Introduction}

Breakthroughs in immunotherapy for cancer patients have changed the clinical practice of treating lung cancer, a deadly disease that causes about 1.8 million deaths worldwide every year (1). Immune checkpoint inhibitors that target the programmed death-1 (PD-1)/programmed death-ligand 1 (PD-L1) have produced significant survival benefits in advanced non-small cell lung cancer (NSCLC) patients. Based on the KEYNOTE-010 (2), CheckMate 017 (3), and 057 trials (4), pembrolizumab and nivolumab monotherapy have been approved for NSCLC patients in whom platinum-doublet chemotherapy has failed. However, only $18-20 \%$ of patients achieve durable responses after receiving salvage anti-PD-1 immunotherapy (5), and most have primary resistance to anti-PD-1 immunotherapy. Thus, predictive biomarkers are needed to identify patients who may benefit from immunotherapy.

Independent predictive biomarkers of immune checkpoint inhibitors, such as PD-L1, (6) and the tumor mutation burden (TMB) (7), have some clinical relevance in the selection of patients; however, these predictive markers are not clinician friendly. The availability of sufficient tissue for subsequent molecular testing [including the epidermal growth factor receptor $(E G F R)$, anaplastic lymphoma kinase $(A L K)$ mutations, PD-L1 expression, and the TMB] is increasingly limited. In addition, up to $30 \%$ of NSCLC patients do not have adequate tissue available at diagnosis for standard biomarker testing $(8,9)$. Additional predictive, easily measured, non-invasive biomarkers are needed to identify the patients who are most likely to benefit from PD-1 inhibitor therapy.

The efficacy of immune checkpoint inhibitors is thought to be heavily dependent on the host's immune system, and body composition is strongly related to the immune system. Skeletal muscle loss, referred to as sarcopenia, is a condition characterized by the loss of skeletal muscle mass and function (10). Patients with sarcopenia tend to have a higher incidence of infectious disease (11), metabolic syndrome (12), insulin resistance (13), and cardiovascular disease (14). Sarcopenia is pathophysiologically related to various etiologies, including advanced age, malnutrition, a lack of exercise, inflammatory diseases, and endocrine diseases (15). As cancer progresses, it causes a state of cachexia, malnutrition and various metabolic disorders, including anorexia, poor nutrition, systemic inflammation, and exacerbates the prognosis and quality of life of patients. Unlike normal malnutrition, cachexia often leads to a decrease in skeletal muscle mass, which is defined as sarcopenia.

Diagnosing sarcopenia is inexpensive, non-invasive, and reproducible. Routine diagnostic imaging using computer tomography (CT) can accurately quantify muscle mass and can be performed as part of daily clinical practice, and measurements of the cross-sectional area of the skeletal muscles of an abdominal CT at the level of the third lumbar vertebra (L3) are widely used to assess sarcopenia. Studies have shown the prognostic value of sarcopenia in various cancers. The survival rate of sarcopenia patients with esophageal cancer (16), and melanoma (17) is significantly lower than that of non-sarcopenic patients. Further, sarcopenia has been reported to be a prognostic factor associated with poor outcomes in lung cancer patients receiving PD-1 inhibitor therapy $(18,19)$. However, previous research has not reported on overall survival (OS), and the sample sizes of previous studies have been small.

Thus, we conducted a retrospective study to examine the relationship between sarcopenia and treatment outcomes, including OS, in advanced NSCLC patients receiving salvage anti-PD-1 immunotherapy.

We present the following article in accordance with the REMARK reporting checklist (available at https://dx.doi. org/10.21037/atm-21-6578).

\section{Methods}

\section{Patients}

To be eligible for inclusion in this study, patients had to meet the following criteria: (I) have histologically confirmed NSCLC; (II) be in stage IV and have disease progression after having previously undergone platinumcontaining systematic therapy or targeted therapy for those with oncogene mutations; (III) have undergone anti-PD-1 monotherapy between January 2015 and December 2019 at the Cancer Center of Sun Yat-sen University; (IV) have complete clinicopathological data for evaluation; and (V) have an Eastern Cooperative Oncology Group (ECOG) performance-status score of $\leq 2$. Patients were excluded from the study if they met any of the following exclusion criteria: (I) had previously undergone therapy with immune checkpoint inhibitors or T-cell stimulation; (II) were aged $<18$ years old; and/or (III) had other malignancies within the last 5 years.

The study was conducted in accordance with the Declaration of Helsinki (as revised in 2013). This study 

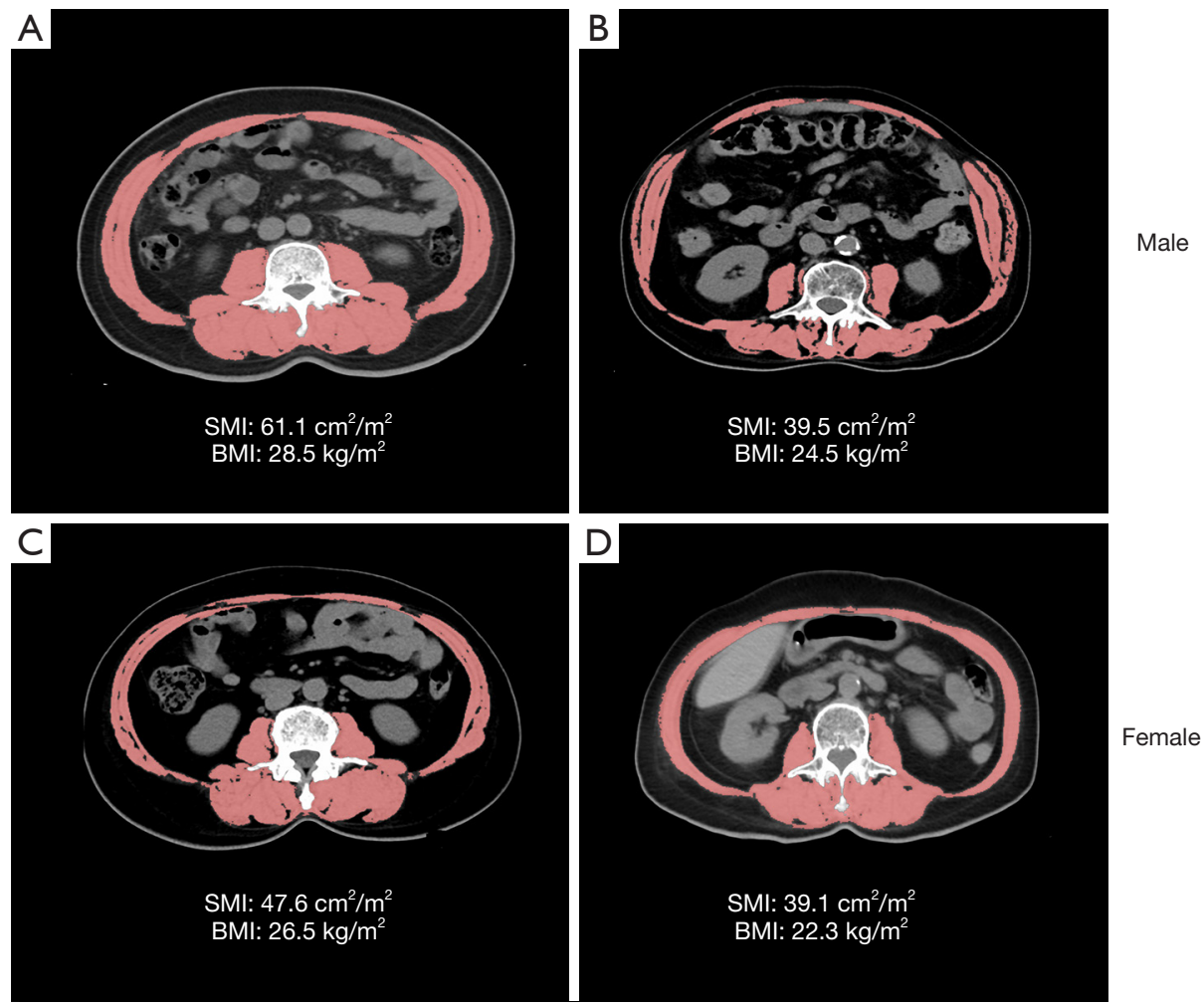

Figure 1 Computed tomography images of typical sarcopenic and non-sarcopenic cases. The skeletal muscle area is shown in red. SMI, skeletal muscle index; BMI, body mass index.

was approved by the Sun Yat-sen University Cancer Center Institutional Review Board (No. B2020-402-01). Because of the retrospective nature of the research, the requirement for informed consent was waived.

\section{Data collection and follow-up}

The patients were followed-up with until March 2021 by hospital records. Our primary study endpoints were OS, defined as the time from the date of the first cycle of front-line therapy to the date of death from any cause, and second-line progression-free survival (PFS), defined as the time from second-line palliative therapy to tumor progression, the last follow-up before the initiation of thirdline therapy, or death from any cause.

\section{Clinicopathological information and sarcopenia}

Detailed clinical information, including age, gender, smoking history, performance status (PS), blood test results, including neutrophil and lymphocyte results, histology, gene mutation, metastatic sites, tumor size, treatment, and follow-up data were obtained for the enrolled patients. Sarcopenia was determined by a surrogate marker: the cross-sectional skeletal muscle surface $\left(\mathrm{cm}^{2}\right)$ at the level of the third vertebra on 2 consecutive transversal computed tomography (CT) images on which both vertebral spines were visible. The CT images were 3 - to 5 -mmthick multiplanar reconstructions contrast enhanced or unenhanced on the axial plane. Osirix ${ }^{\mathrm{TM}}$ version 7.0 (32 bit; http://www.osirix-viewer.com) was used to obtain measurements. The "Grow Region (2D/3D Segmentation)" tool was used to automatically select all the skeletal muscle mass in 1 transversal CT image. The distinction between different tissues was based on Hounsfield units. The following muscles were measured: the psoas, paraspinal, transverse abdominal, external oblique, internal oblique, and rectus abdominis muscles. A threshold range of -30 to +110 Hounsfield units was used for the skeletal muscle (see Figure $1 A-1 D)$. Muscle area $\left(\mathrm{cm}^{2}\right)$ was standardized for height in meters squared $\left(\mathrm{m}^{2}\right)$ and reported as the lumbar skeletal muscle index (SMI) $\left(\mathrm{cm}^{2} / \mathrm{m}^{2}\right)$. Adopting the 
Table 1 Basic clinicopathological characteristics

\begin{tabular}{|c|c|c|}
\hline Characteristic & Subcategory & No. of patients (\%) \\
\hline \multirow[t]{2}{*}{ Age, years } & $\leq 55$ & $54(51.4)$ \\
\hline & $>55$ & $51(48.6)$ \\
\hline \multirow[t]{2}{*}{ Gender } & Female & $32(30.5)$ \\
\hline & Male & $73(69.5)$ \\
\hline \multirow[t]{2}{*}{ Smoking history } & Never smoked & $69(65.7)$ \\
\hline & Current/ex-smoker & $36(34.3)$ \\
\hline \multirow{2}{*}{$\begin{array}{l}\text { Performance status } \\
\text { (ECOG) }\end{array}$} & 0 & $46(43.8)$ \\
\hline & $\geq 1$ & $59(56.2)$ \\
\hline \multirow[t]{2}{*}{ Histology } & Non-squamous & $74(70.5)$ \\
\hline & Squamous & $31(29.5)$ \\
\hline \multirow[t]{2}{*}{ Size } & $\leq 5 \mathrm{~cm}$ & $73(69.5)$ \\
\hline & $>5 \mathrm{~cm}$ & $32(30.5)$ \\
\hline \multirow[t]{2}{*}{ Sarcopenia } & Yes & $38(36.2)$ \\
\hline & No & $67(63.8)$ \\
\hline \multirow[t]{3}{*}{ Drug } & Nivolumab & 35 (33.3) \\
\hline & Pembrolizumab & $46(43.8)$ \\
\hline & Camrelizumab & $24(22.9)$ \\
\hline \multirow[t]{2}{*}{$\mathrm{BMI}$} & $<25 \mathrm{~kg} / \mathrm{m}^{2}$ & $84(80.0)$ \\
\hline & $\geq 25 \mathrm{~kg} / \mathrm{m}^{2}$ & $21(20.0)$ \\
\hline \multirow[t]{2}{*}{ NLR } & $<3$ & $47(44.8)$ \\
\hline & $\geq 3$ & $58(55.2)$ \\
\hline \multirow[t]{2}{*}{ Liver metastasis } & No & $80(76.2)$ \\
\hline & Yes & $25(23.8)$ \\
\hline \multirow[t]{2}{*}{ Brain metastasis } & No & $75(71.4)$ \\
\hline & Yes & $30(28.6)$ \\
\hline \multirow[t]{2}{*}{ Lung metastasis } & No & $54(51.4)$ \\
\hline & Yes & $51(48.6)$ \\
\hline \multirow{2}{*}{$\begin{array}{l}\text { No. of metastatic } \\
\text { sites }\end{array}$} & $\leq 2$ & $56(53.3)$ \\
\hline & $>2$ & $49(46.7)$ \\
\hline \multirow{3}{*}{$\begin{array}{l}\text { EGFR or } A L K \\
\text { mutation }\end{array}$} & No & $74(70.5)$ \\
\hline & Yes & $19(18.1)$ \\
\hline & Unknown & $12(11.4)$ \\
\hline
\end{tabular}

ECOG, Eastern Cooperative Oncology Group; BMI, body mass index; NLR, neutrophil-to-lymphocyte ratio; EGFR, epidermal growth factor receptor; ALK, anaplastic lymphoma kinase. approach of Martin et al. (20), sarcopenia was defined as SMI $<41 \mathrm{~cm}^{2} / \mathrm{m}^{2}$ in women regardless of their BMI and SMI $<43 \mathrm{~cm}^{2} / \mathrm{m}^{2}$ in men with a BMI $<25 \mathrm{~kg} / \mathrm{m}^{2}$, and SMI $<53 \mathrm{~cm}^{2} / \mathrm{m}^{2}$ in for men with a BMI $>25 \mathrm{~kg} / \mathrm{m}^{2}$.

\section{Statistical analysis}

Statistical analyses were performed using SPSS 22.0 (IBM, Chicago, IL, USA) and R for Windows (version 3.6.2, http://www.r-proje ct.org/). The Chi square test was used to assess the univariate relationship between the clinicopathologic variables. The Kaplan-Meier method and the log-rank test were used to investigate and compare prognostic roles in predicting PFS and OS. Univariate and multivariate regression analyses were conducted to analyze the risk factors. All the statistical tests were two-sided, and $\mathrm{P}$ values $<0.05$ were considered statistically significant.

\section{Results}

\section{Patient characteristics}

In total, 105 patients with stage IV NSCLC with available sarcopenia and other clinicopathological data were included in the analysis. Their basic characteristics are shown in Table 1. Of the patients, 73 were male (69.5\%), and 32 were female (30.5\%). Patients had a median age of 55 years (range, 28-77 years). Most patients had no history of smoking (69, 65.7\%), a tumor size $<5 \mathrm{~cm}(73,69.5 \%)$, a non-oncogene mutation status $(74,70.5 \%)$, and a histology of non-squamous cancer (74, 70.5\%). Approximately $20.0 \%$ of patients had a BMI $>25 \mathrm{~kg} / \mathrm{m}^{2}$, and more than half (59, $56.2 \%)$ had a PS $>1$. Nearly half of the patients had more than 2 metastatic sites, and the lung was the most common metastatic location $(51,48.6 \%)$. Thirty patients $(28.6 \%)$ had brain metastasis, and 25 patients $(23.8 \%)$ had liver metastasis. Fifty-eight patients $(55.2 \%)$ had a neutrophilto-lymphocyte ratio (NLR) $>3$. The anti-PD-1 drugs used in the study were nivolumab $(35,33.3 \%)$, pembrolizumab (46, 43.8\%), and camrelizumab (24, 22.9\%). Thirty-eight patients $(36.2 \%)$ were diagnosed with sarcopenia based on the SMI cut-offs.

\section{Sarcopenia and correlations with clinicopatbology}

The correlations between sarcopenia and other clinicopathologic factors are summarized in Table 2. Notably, 26 (44.8\%) of 58 patients with a NLR $\geq 3$ exhibited 
Table 2 The correlation between sarcopenia and clinicopathologic factors

\begin{tabular}{|c|c|c|c|}
\hline Characteristic & \multicolumn{2}{|c|}{ Sarcopenia status, n (\%) } & $P$ value \\
\hline Age & & & 0.531 \\
\hline$\leq 55$ years & $36(53.7)$ & $18(47.4)$ & \\
\hline$>55$ years & $31(46.3)$ & $20(52.6)$ & \\
\hline Female & $21(31.3)$ & $11(28.9)$ & \\
\hline Male & $46(68.7)$ & $27(71.1)$ & \\
\hline Smoking history & & & 0.66 \\
\hline Never smoke & $43(64.2)$ & $26(68.4)$ & \\
\hline 0 & $30(44.8)$ & $16(42.1)$ & \\
\hline$\geq 1$ & $37(55.2)$ & $22(57.9)$ & \\
\hline Histology & & & 0.922 \\
\hline Non-squamous & $47(70.1)$ & $27(71.1)$ & \\
\hline Squamous & $20(29.9)$ & $11(28.9)$ & \\
\hline Size & & & 0.531 \\
\hline$\leq 5 \mathrm{~cm}$ & 48 (71.6) & $25(65.8)$ & \\
\hline$>5 \mathrm{~cm}$ & $19(28.4)$ & $13(34.2)$ & \\
\hline$<25 \mathrm{~kg} / \mathrm{m}^{2}$ & $13(19.4)$ & $8(21.1)$ & \\
\hline$\geq 25 \mathrm{~kg} / \mathrm{m}^{2}$ & $54(80.6)$ & 30 (78.9) & \\
\hline NLR & & & 0.041 \\
\hline$<3$ & $35(52.2)$ & $12(31.6)$ & \\
\hline$\geq 3$ & $32(47.8)$ & $26(68.4)$ & \\
\hline Liver metastasis & & & 0.617 \\
\hline No & $50(74.6)$ & $30(78.9)$ & \\
\hline Yes & $17(25.4)$ & $8(21.1)$ & \\
\hline Brain metastasis & & & 0.607 \\
\hline No & $49(73.1)$ & $26(68.4)$ & \\
\hline Yes & $18(26.9)$ & $12(31.6)$ & \\
\hline
\end{tabular}

Table 2 (continued) 
Table 2 (continued)

\begin{tabular}{lcc}
\hline \multirow{2}{*}{ Characteristic } & \multicolumn{2}{c}{ Sarcopenia status, $\mathrm{n}(\%)$} \\
\cline { 2 - 3 } & \multicolumn{1}{c}{ Non-sarcopenia $(\mathrm{n}=67)$} & Sarcopenia $(\mathrm{n}=38)$ \\
No. of metastatic sites & $34(50.7)$ & $22(57.9)$ \\
$\leq 2$ & $33(49.3)$ & $16(42.1)$ \\
$>2$ & & \\
EGFR or ALK mutation & $49(73.2)$ & $25(65.8)$ \\
No & $10(14.9)$ & $9(23.7)$ \\
Yes & $8(11.9)$ & $4(10.5)$ \\
Unknown & & 0.534 \\
\hline
\end{tabular}

ECOG, Eastern Cooperative Oncology Group; BMI, body mass index; NLR, neutrophil-to-lymphocyte ratio; EGFR, epidermal growth factor receptor; ALK, anaplastic lymphoma kinase.
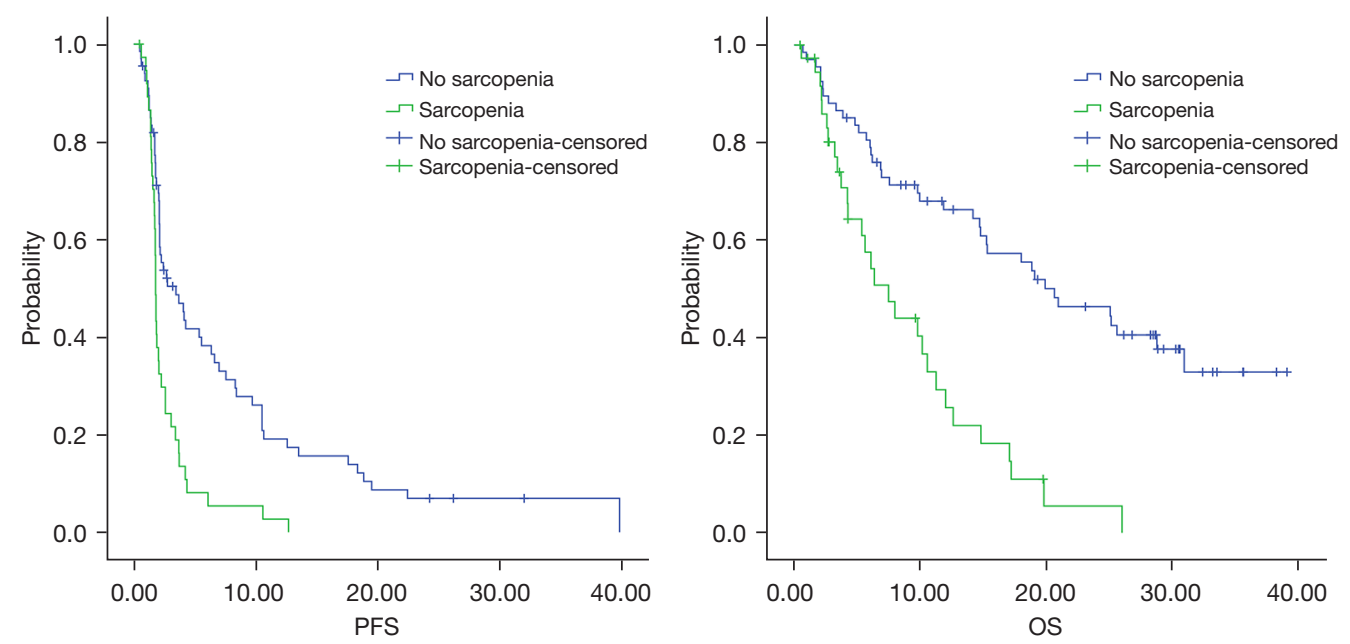

Figure 2 Kaplan-Meier survival curves for the sarcopenia and non-sarcopenia groups. (A) The PFS was significantly worse in the sarcopenia group than the non-sarcopenia group (2.67 vs. 7.96 months; $\mathrm{P}<0.001)$. (B) The OS was significantly worse in the sarcopenia group than the non-sarcopenia group (9.08 vs. 21.84 months; $\mathrm{P}<0.001$ ). PFS, progression-free survival; OS, overall survival.

sarcopenia, while only $12(25.5 \% ; \mathrm{P}=0.041)$ of 47 patients with a NLR $<3$ exhibited sarcopenia. Sarcopenia was not correlated with other clinicopathological factors, including age $(\mathrm{P}=0.531)$, gender $(\mathrm{P}=0.796)$, smoking $(\mathrm{P}=0.660)$, histology $(\mathrm{P}=0.922)$, $\mathrm{PS}(\mathrm{P}=0.791)$, $\mathrm{BMI}(\mathrm{P}=0.839)$, tumor size $(\mathrm{P}=0.531)$, or the number of metastatic sites $(\mathrm{P}=0.480)$.

\section{Survival analysis}

The median follow-up time for all patients was 14.73 months (range, 0.47-39.13 months). The median OS of the 105 patients was 14.7 months [95\% confidence interval (CI):
10.9-18.6 months]. The Kaplan-Meier analysis revealed that patients with sarcopenia had a worse PFS and OS than those without sarcopenia (PFS: 2.67 vs. 7.96 months, respectively; $\mathrm{P}<0.001$; OS: 9.08 vs. 21.84 months, respectively; $\mathrm{P}<0.001$; see Figure 2). The univariate Cox regression analysis also showed that patients with sarcopenia had a lower PFS [hazards ratio (HR) 2.31; $\mathrm{P}<0.001$; see Table 3] and OS (HR 3.18; $\mathrm{P}<0.001$; see Table 4) than those without sarcopenia. Further, in a multivariable Cox regression model for OS adjusted for age, gender, PS, and the NLR, sarcopenia was found to be independently associated with poor OS (HR 3.068; 95\% CI: 1.329-7.084; $\mathrm{P}=0.009$; see Table 4). In a 
Table 3 Cox analyses of risk of the effects of sarcopenia and clinicopathological factors on PFS in patients receiving salvage anti-PD-1 immunotherapy

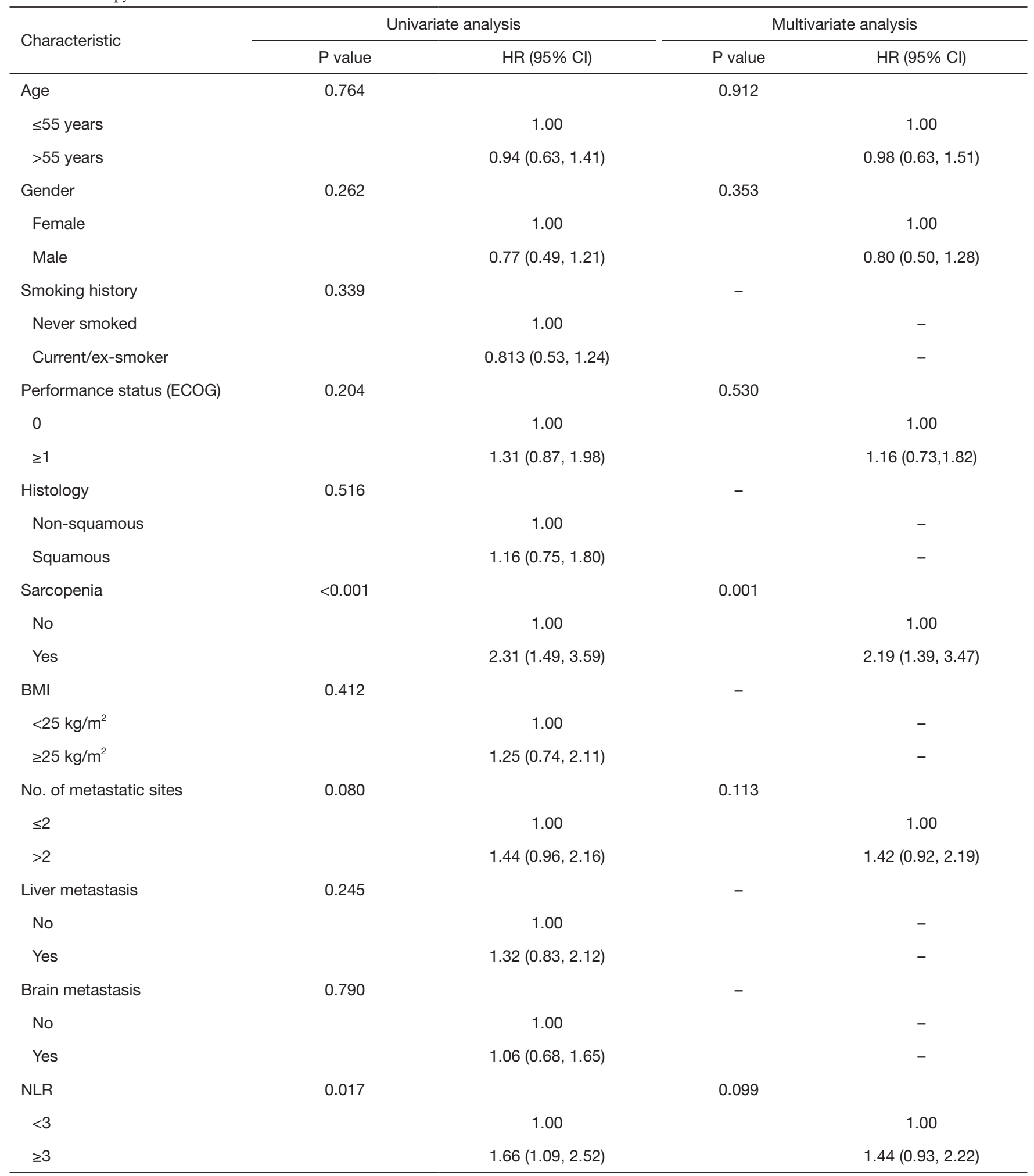

Table 3 (continued) 
Table 3 (continued)

\begin{tabular}{lccc}
\hline \multirow{2}{*}{ Characteristic } & \multicolumn{2}{c}{ Univariate analysis } & \multicolumn{2}{c}{ Multivariate analysis } \\
\cline { 2 - 4 } & P value & $\mathrm{HR}(95 \% \mathrm{Cl})$ & $\mathrm{P}$ value \\
\hline EGFR or ALK mutation & & 1.00 & - \\
No & 0.700 & $1.11(0.64,1.94)$ & - \\
Yes & 0.470 & $1.27(0.66,2.42)$ & - \\
Unknown & 0.767 & 1.00 & - \\
Size & & $0.94(0.60,1.46)$ & - \\
$>5 \mathrm{~cm}$ & &
\end{tabular}

PFS, progression-free survival; $\mathrm{Cl}$, confidence interval; HR, hazard ratio; ECOG, Eastern Cooperative Oncology Group; BMI, body mass index; NLR, neutrophil-to-lymphocyte ratio; EGFR, epidermal growth factor receptor; ALK, anaplastic lymphoma kinase.

Table 4 Cox analyses of the risk of sarcopenia and clinicopathological factors on OS in patients receiving salvage anti-PD-1 immunotherapy

\begin{tabular}{|c|c|c|c|c|}
\hline Characteristic & \multicolumn{2}{|c|}{ Univariate analysis } & \multicolumn{2}{|c|}{ Multivariate analysis } \\
\hline Age & - & & - & \\
\hline$\leq 55$ years & & 1.00 & & 1.00 \\
\hline$>55$ years & & $1.19(0.74,1.93)$ & & $1.29(0.80,2.10)$ \\
\hline Female & & 1.00 & & 1.00 \\
\hline Male & & $1.18(0.85,2.58)$ & & $1.64(0.93,2.90)$ \\
\hline Smoking history & 0.681 & & - & \\
\hline Never smoke & & 1.00 & & - \\
\hline 0 & & 1.00 & & 1.00 \\
\hline$\geq 1$ & & $1.43(0.88,2.33)$ & & $1.39(0.85,2.30)$ \\
\hline Histology & 0.176 & & - & \\
\hline Non-squamous & & 1.00 & & - \\
\hline Squamous & & $1.43(0.85,2.39)$ & & - \\
\hline Sarcopenia & $<0.001$ & & $<0.001$ & \\
\hline No & & 1.00 & & 1.00 \\
\hline Yes & & $3.18(1.89,5.33)$ & & $2.85(1.69,4.84)$ \\
\hline
\end{tabular}

Table 4 (continued) 
Table 4 (continued)

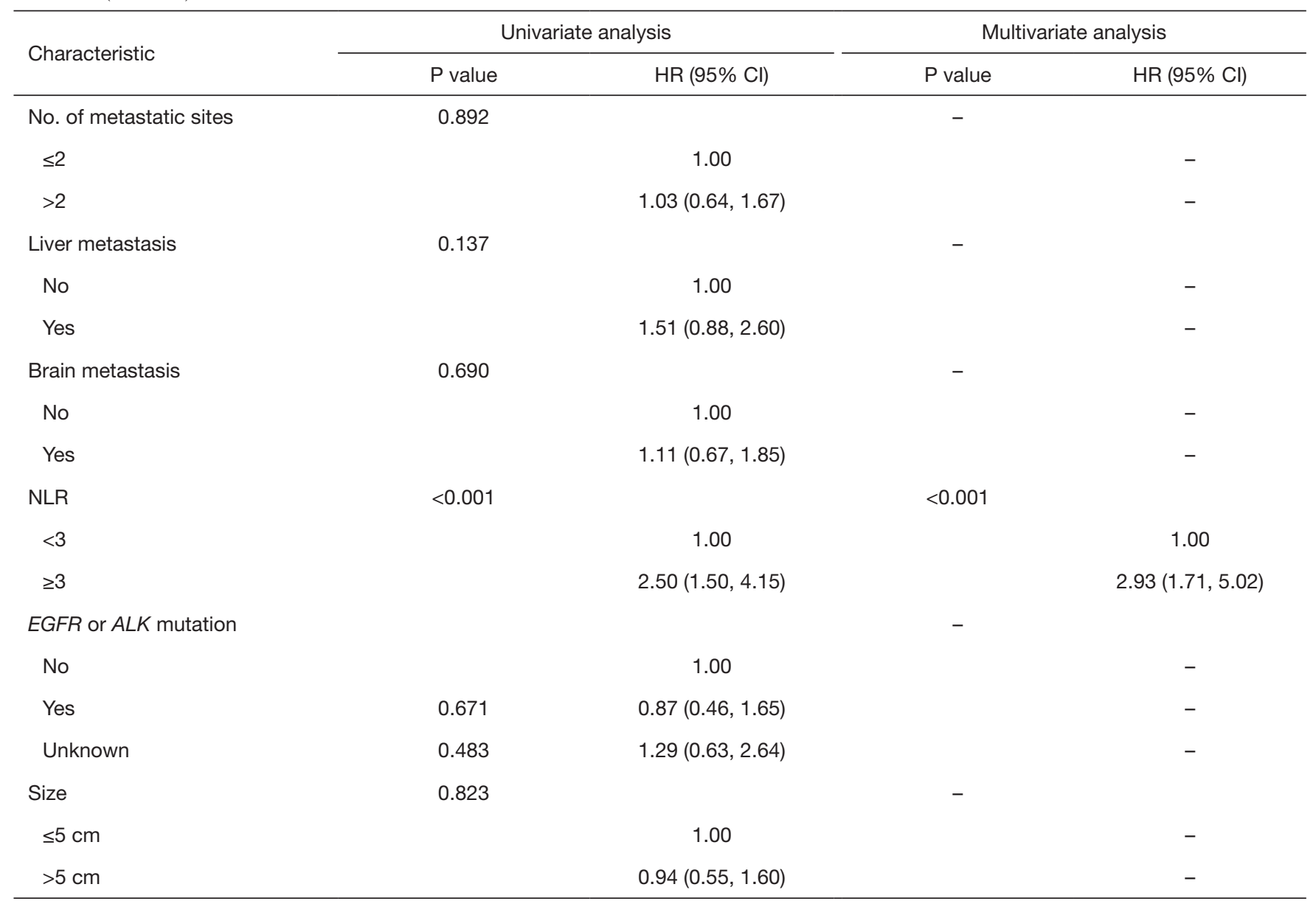

OS, overall survival; Cl, confidence interval; HR, hazard ratio; ECOG, Eastern Cooperative Oncology Group; BMI, body mass index; NLR, neutrophil-to-lymphocyte ratio; EGFR, epidermal growth factor receptor; ALK, anaplastic lymphoma kinase.

multivariable Cox regression model for PFS, sarcopenia was found to be independently associated with poor PFS (HR 2.19; 95\% CI: 1.39-3.47; $\mathrm{P}=0.001$; see Table 3). Patients with a NLR of $\geq 3$ also showed worse PFS (HR 1.66; $\mathrm{P}=0.017$; see Table 3) in the univariate Cox regression analysis, and worse OS in both the univariate (HR 2.50; $\mathrm{P}<0.001$; see Table 4) and multivariate (HR 2.93; $\mathrm{P}<0.001$; see Table 4) Cox regression analyses.

The association between sarcopenia and the efficacy of anti-PD-1 immunotherapy was further confirmed in all subgroups (see Figure 3). Patients with sarcopenia had worse OS regardless of their age, smoking history, histology, tumor size, number of metastatic sites, brain metastasis, and NLR. Notably, no correlation was found between OS and being female (HR 2.12; $\mathrm{P}=0.081$ ), having a high ECOG (HR 1.42; $\mathrm{P}=0.216$ ), a low BMI (HR 2.17; $\mathrm{P}=0.125)$, the $E G F R$ or $A L K$ mutation (HR 1.89; $\mathrm{P}=0.232$ ), $>2$ metastasis (HR 1.75; $\mathrm{P}=0.090)$, or liver metastasis (HR 2.39; $\mathrm{P}=0.062$ ).

\section{Discussion}

As far as we know, this is the largest study to examine the relationship between sarcopenia and immunotherapy, especially in relation to OS, in advanced NSCLC patients receiving salvage anti-PD-1 immunotherapy. We found that patients with sarcopenia receiving salvage anti-PD-1 immunotherapy showed significantly worse PFS and OS than their non-sarcopenic counterparts. In addition, we found that sarcopenia was associated with the NLR, and the NLR also acted as a predictor of OS. Measures of sarcopenia and inflammation are easily obtained in the clinical setting and are each independent powerful 


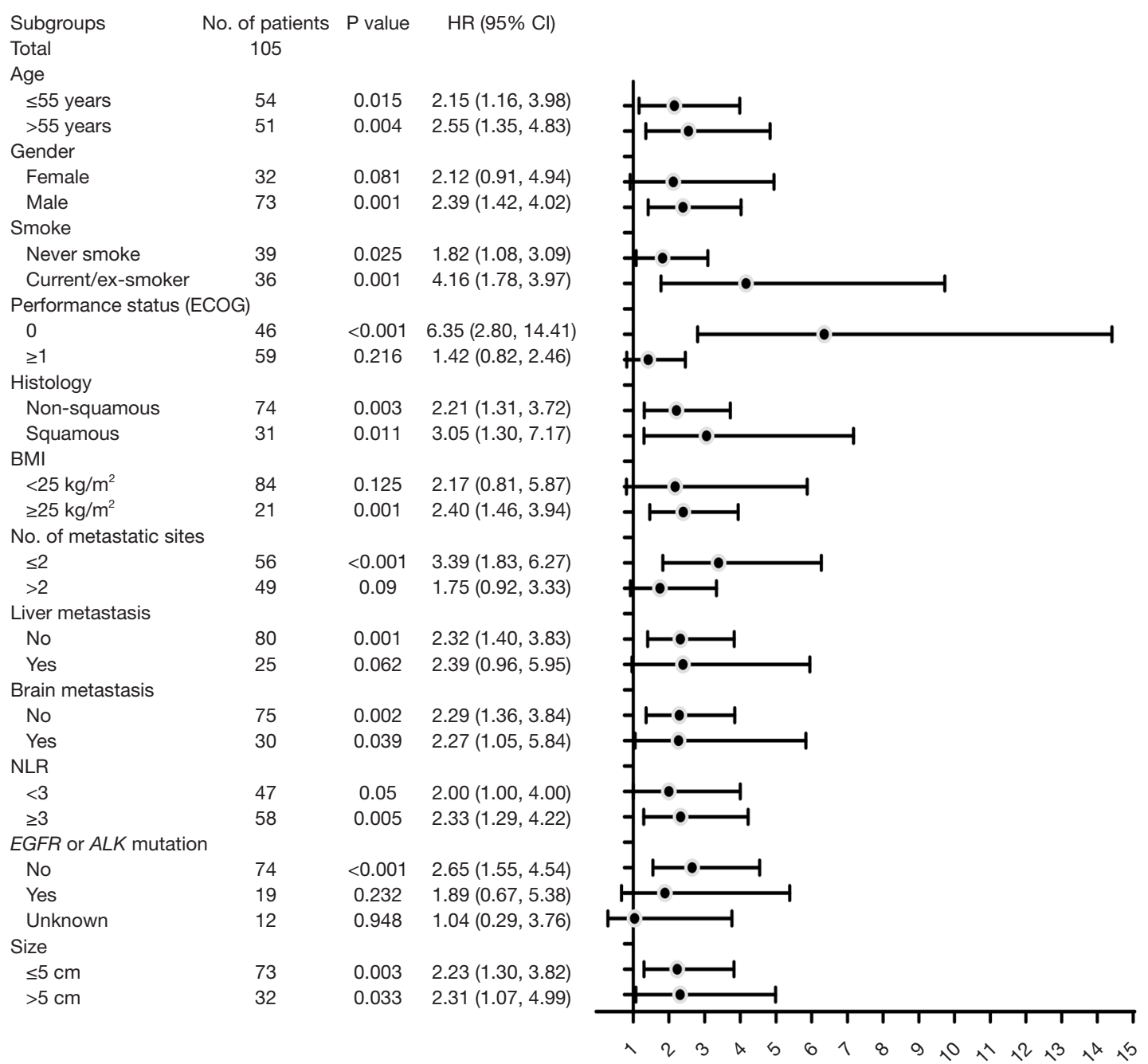

Figure 3 The association between sarcopenia and the efficacy of anti-PD-1 immunotherapy was confirmed in all the subgroups. CI, confidence interval; HR, hazard ratio; ECOG, Eastern Cooperative Oncology Group; BMI, body mass index; NLR, neutrophil-tolymphocyte ratio; EGFR, epidermal growth factor receptor; ALK, anaplastic lymphoma kinase.

prognostic indicators in patients receiving anti-PD-1 immunotherapy.

In this study, we found that patients with sarcopenia had worse PFS and OS than those without sarcopenia. Body composition has been found to be an important prognostic factor in many illnesses, including chronic diseases (21), critical care (22), and the elderly population (23). Body composition measurements are simple and quick to obtain from CT, which is a routine part of preoperative cancer staging. Thus, such assessments do not incur additional costs or increase patients' exposure to ionizing radiation. Cancer cachexia is a multifactorial syndrome characterized by progressive weight loss due to the depletion of adipose tissue and skeletal muscle mass. The presence of sarcopenia indicates tumor aggressiveness. It develops as a result of tumor progression, tumor-induced systemic inflammation, or metabolic aberration. Patients with sarcopenia are characterized by poor general health and physical performance, which can contribute to a worse prognosis in cancer-bearing patients (24). Prado et al. showed that sarcopenia is an independent predictor of worse OS in patients with gastrointestinal or respiratory cancer for the first time (25).

To date, the limited research on NSCLC patients treated with PD-1 therapy indicates that sarcopenia is associated with worse PFS (18). We investigated the association 
between sarcopenia and the efficacy and long-term effects of the PD-1 blockade in patients receiving salvage antiPD-1 immunotherapy. In our cohort, the PFS of patients with sarcopenia was 2.67 months, and the PFS of patients without sarcopenia was 7.96 months. The OS of patients with sarcopenia was 9.08 months, and the OS of patients without sarcopenia was 21.84 months. Thus, the effects of sarcopenia should not be ignored in routine practice. A baseline skeletal muscle mass may be critical to the longterm response of patients undergoing $\mathrm{PD}-1$ inhibitor therapy.

Given the prognostic significance of sarcopenia in NSCLC, the prevention of or recovery from sarcopenia and cancer cachexia could inform the selection of patients who may benefit from anti-PD-1 immunotherapy. In the subgroups, the patients with sarcopenia had worse OS regardless of their age, smoking history, histology, tumor size, number of metastatic sites, brain metastasis, and NLR. It is difficult to accurately interpret sex-based differences, as other factors, such as ethnicity and genetic predispositions, may affect the prevalence of sarcopenia. There was also no difference in the poor PS and low BMI of patients with or without sarcopenia. Indeed, patients with a poor PS and low BMI tended to have less skeletal muscle mass, but these variables were considered not to have an independent role in PFS and OS.

The mechanism underlying sarcopenia and poor outcomes remains uncertain. An increased understanding of the underlying mechanisms of muscle loss in cancer patients could help to formulate treatment strategies. Skeletal muscle wasting is a comprehensive result of an imbalance between synthetic and degradative protein pathways, increased muscle cell apoptosis, and decreased regenerative capacity (26). Another important function of skeletal muscle is that it is an organ of cytokines and other peptide denominated myokines (e.g., interleukin-6, interleukin-8, and interleukin-15), which are key factors in muscle, and are extensively involved in inflammatory processes (27). These cytokines and myokines have systemic effects on anti-tumor immune responses (28). Thus, we speculate that a decrease in myokines due to skeletal muscle loss may lead to a poor response to $\mathrm{PD}-1$ inhibitors.

Chronic inflammation is one reason why sarcopenia affects immunotherapy, resulting in tumor cell escape form immunity through many mechanisms. Notably, we found that the NLR, which is an inflammatory biomarker, is a significant prognostic factor in predicting OS. Inflammation is also known to be a major factor driving the development and progression of cancer. It is a potential biomarker for NSCLC patients treating with immune checkpoint inhibitor (29). The NLR is a simple and convenient measurement that can be obtained at any clinical visit simply by drawing peripheral blood. The NLR was found to be a strong prognostic marker associated with worse OS in NSCLC patients in the pre-immunotherapy era (30). Currently, the role of the NLR has been refocused and reassessed, as immune cells are the main immunotherapy tools for fighting cancers. Numerous reports have found the NLR to be correlated with NSCLC immunotherapy outcomes (31). The immunosuppression induced by chronic inflammation is caused by increased immunosuppressive cells in tumor sites. Notably, myeloid-derived suppressor cells (MDSCs) are strongly related to immunosuppression (32). Further, MDSCs are inducted into tumor cells by chronic inflammation, which not only inhibits the entry of cluster of differentiation $8^{+}\left(\mathrm{CD} 8^{+}\right) \mathrm{T}$ cells into tumor tissue, but also induces regulatory $\mathrm{T}$ cells (Tregs) to suppress immune responses (33). Thus, MDSCs and Tregs increased by chronic inflammation will have great influence on the immunotherapeutic effect (34).

Sarcopenia, a multifactorial syndrome characterized by on-going skeletal muscle wasting, has been observed in patients with advanced cancer. Recognizing the importance of sarcopenia on outcomes has led to further research on how to increase or prevent the further loss of muscle mass. As sarcopenia results from decreased protein synthesis and increased protein degradation, protein supplementation can play a key role in nutritional support (35). Many treatments, including exercise (36), omega-3 fatty acid dietary supplementation (37), and novel treatments, including melanocortin-4 receptor antagonists (38), myostatin inhibition (39), beta-blockers, interleukin-6 antagonists (40), synthetic ghrelin, and vitamin D (41), are being explored. Previous research has shown that thymosin alpha 1 (Ta1) might play a role in improving the treatment effect of antiPD-1 immunotherapy, which is thought to be related to its immunomodulating activities (42). Further research on the effects of these and other interventions needs to be conducted to improve the prognosis of advanced cancer patients. We believe that the prevention of sarcopenia and the development of predictive biomarkers are both important in deriving future benefits from immune checkpoint inhibitors.

This study had several limitations. First, it was retrospective in nature and did not have a large sample size; thus, deviations and confounding factors may have 
affected the results. Second, data on the proinflammatory cytokines or the other pro-catabolism factors produced by tumors were not available for our patients. Finally, due to a lack of information regarding PD-L1 expression and the TMB, we were unable to include these variables in our analyses. However, we believe that the results of the present study may stimulate further investigations that can better elucidate the association between sarcopenia and treatments.

In conclusion, based on this retrospective analysis, advanced NSCLC patients with sarcopenia undergoing salvage immunotherapy have a poor prognosis. Screening for sarcopenia could help to identify patients who may benefit from immunotherapy in clinical settings. Further research needs to be conducted to verify the clinical biomarkers involved in immune checkpoint inhibitor responses.

\section{Acknowledgments}

Funding: This study was funded by grants from the Science and Technology Program of Guangdong Province (2019A1515011596), the National Natural Science Funds of China (81903176), and the Medical Scientific Research Foundation of Guangdong Province (C2019110). The funding sources had no role in the design and conduct of the study, the collection, management, analysis, and interpretation of the data, the preparation, review, or approval of the manuscript, or the decision to submit the manuscript for publication.

\section{Footnote}

Reporting Checklist: The authors have completed the REMARK reporting checklist. Available at https://dx.doi. org/10.21037/atm-21-6578

Data Sharing Statement: Available at https://dx.doi. org/10.21037/atm-21-6578

Conflicts of Interest: All authors have completed the ICMJE uniform disclosure form (available at https://dx.doi. org/10.21037/atm-21-6578). The authors have no conflicts of interest to declare.

Ethical Statement: The authors are accountable for all aspects of the work, including ensuring that any questions related to the accuracy or integrity of any part of the work have been appropriately investigated and resolved. The study was conducted in accordance with the Declaration of Helsinki (as revised in 2013). This study was approved by the Sun Yatsen University Cancer Center Institutional Review Board (No. B2020-402-01). Because of the retrospective nature of the research, the requirement for informed consent was waived.

Open Access Statement: This is an Open Access article distributed in accordance with the Creative Commons Attribution-NonCommercial-NoDerivs 4.0 International License (CC BY-NC-ND 4.0), which permits the noncommercial replication and distribution of the article with the strict proviso that no changes or edits are made and the original work is properly cited (including links to both the formal publication through the relevant DOI and the license). See: https://creativecommons.org/licenses/by-nc-nd/4.0/.

\section{References}

1. Siegel RL, Miller KD, Jemal A. Cancer statistics, 2020. CA Cancer J Clin 2020;70:7-30.

2. Herbst RS, Baas P, Kim DW, et al. Pembrolizumab versus docetaxel for previously treated, PD-L1-positive, advanced non-small-cell lung cancer (KEYNOTE-010): a randomised controlled trial. Lancet 2016;387:1540-50.

3. Brahmer J, Reckamp KL, Baas P, et al. Nivolumab versus Docetaxel in Advanced Squamous-Cell Non-Small-Cell Lung Cancer. N Engl J Med 2015;373:123-35.

4. Borghaei H, Paz-Ares L, Horn L, et al. Nivolumab versus Docetaxel in Advanced Nonsquamous Non-Small-Cell Lung Cancer. N Engl J Med 2015;373:1627-39.

5. Rittmeyer A, Barlesi F, Waterkamp D, et al. Atezolizumab versus docetaxel in patients with previously treated non-small-cell lung cancer (OAK): a phase 3, openlabel, multicentre randomised controlled trial. Lancet 2017;389:255-65.

6. Fehrenbacher L, Spira A, Ballinger M, et al. Atezolizumab versus docetaxel for patients with previously treated non-small-cell lung cancer (POPLAR): a multicentre, open-label, phase 2 randomised controlled trial. Lancet 2016;387:1837-46.

7. Wan L, Wang Z, Xue J, et al. Tumor mutation burden predicts response and survival to immune checkpoint inhibitors: a meta-analysis. Transl Cancer Res 2020;9:5437-49.

8. Tischer B, Kim E, Peters M, et al. Physician patterns of care in patients with EGFR mutation+ NSCLC: an 
international survey into testing and treatment choice. J Thorac Oncol 2017;12:S1199-200.

9. Green MR, Willey J, Buettner A, et al. Molecular testing prior to first-line therapy in patients with stage IV nonsquamous non-small cell lung cancer (NSCLC): A survey of U.S. medical oncologists. J Clin Oncol 2014;26:abstr 8097.

10. Rosenberg IH. Sarcopenia: origins and clinical relevance. J Nutr 1997;127:990S-1S.

11. Cosquéric G, Sebag A, Ducolombier C, et al. Sarcopenia is predictive of nosocomial infection in care of the elderly. Br J Nutr 2006;96:895-901.

12. Lee J, Hong YP, Shin HJ, et al. Associations of Sarcopenia and Sarcopenic Obesity With Metabolic Syndrome Considering Both Muscle Mass and Muscle Strength. J Prev Med Public Health 2016;49:35-44.

13. Kim JE, Lee YH, Huh JH, et al. Early-stage chronic kidney disease, insulin resistance, and osteoporosis as risk factors of sarcopenia in aged population: the fourth Korea National Health and Nutrition Examination Survey (KNHANES IV), 2008-2009. Osteoporos Int 2014;25:2189-98.

14. Kim JH, Cho JJ, Park YS. Relationship between sarcopenic obesity and cardiovascular disease risk as estimated by the Framingham risk score. J Korean Med Sci 2015;30:264-71.

15. Cruz-Jentoft AJ, Baeyens JP, Bauer JM, et al. Sarcopenia: European consensus on definition and diagnosis: Report of the European Working Group on Sarcopenia in Older People. Age Ageing 2010;39:412-23.

16. Harada K, Ida S, Baba Y, et al. Prognostic and clinical impact of sarcopenia in esophageal squamous cell carcinoma. Dis Esophagus 2016;29:627-33.

17. Sabel MS, Lee J, Cai S, et al. Sarcopenia as a prognostic factor among patients with stage III melanoma. Ann Surg Oncol 2011;18:3579-85.

18. Nishioka N, Uchino J, Hirai S, et al. Association of Sarcopenia with and Efficacy of Anti-PD-1/PD-L1 Therapy in Non-Small-Cell Lung Cancer. J Clin Med 2019;8:450.

19. Shiroyama T, Nagatomo I, Koyama S, et al. Impact of sarcopenia in patients with advanced non-small cell lung cancer treated with PD-1 inhibitors: A preliminary retrospective study. Sci Rep 2019;9:2447.

20. Martin L, Birdsell L, Macdonald N, et al. Cancer cachexia in the age of obesity: skeletal muscle depletion is a powerful prognostic factor, independent of body mass index. J Clin Oncol 2013;31:1539-47.

21. Koo HK, Park JH, Park HK, et al. Conflicting role of sarcopenia and obesity in male patients with chronic obstructive pulmonary disease: Korean National Health and Nutrition Examination Survey. PLoS One 2014;9:e110448.

22. Muscaritoli M, Lucia S, Molfino A. Sarcopenia in critically ill patients: the new pandemia. Minerva Anestesiol 2013;79:771-7.

23. Du Y, Karvellas CJ, Baracos V, et al. Sarcopenia is a predictor of outcomes in very elderly patients undergoing emergency surgery. Surgery 2014;156:521-7.

24. Fearon KC, Glass DJ, Guttridge DC. Cancer cachexia: mediators, signaling, and metabolic pathways. Cell Metab 2012;16:153-66.

25. Prado CM, Lieffers JR, McCargar LJ, et al. Prevalence and clinical implications of sarcopenic obesity in patients with solid tumours of the respiratory and gastrointestinal tracts: a population-based study. Lancet Oncol 2008;9:629-35.

26. Argilés JM, Busquets S, Stemmler B, et al. Cachexia and sarcopenia: mechanisms and potential targets for intervention. Curr Opin Pharmacol 2015;22:100-6.

27. Pratesi A, Tarantini F, Di Bari M. Skeletal muscle: an endocrine organ. Clin Cases Miner Bone Metab 2013;10:11-4

28. Scharping NE, Menk AV, Moreci RS, et al. The Tumor Microenvironment Represses T Cell Mitochondrial Biogenesis to Drive Intratumoral T Cell Metabolic Insufficiency and Dysfunction. Immunity 2016;45:374-88.

29. Park W, Lopes G. Perspectives: Neutrophil-to-lymphocyte Ratio as a Potential Biomarker in Immune Checkpoint Inhibitor for Non-Small-Cell Lung Cancer. Clin Lung Cancer 2019;20:143-7.

30. Zhang H, Xia H, Zhang L, et al. Clinical significance of preoperative neutrophil-lymphocyte vs plateletlymphocyte ratio in primary operable patients with nonsmall cell lung cancer. Am J Surg 2015;210:526-35.

31. Diem S, Schmid S, Krapf M, et al. Neutrophil-toLymphocyte ratio (NLR) and Platelet-to-Lymphocyte ratio (PLR) as prognostic markers in patients with nonsmall cell lung cancer (NSCLC) treated with nivolumab. Lung Cancer 2017;111:176-81.

32. Youn JI, Gabrilovich DI. The biology of myeloidderived suppressor cells: the blessing and the curse of morphological and functional heterogeneity. Eur J Immunol 2010;40:2969-75.

33. Ostrand-Rosenberg S. Myeloid-derived suppressor cells: more mechanisms for inhibiting antitumor immunity. Cancer Immunol Immunother 2010;59:1593-600. 
34. Kumar R, Collins D, Dolly S, et al. Targeting the PD-1/ PD-L1 axis in non-small cell lung cancer. Curr Probl Cancer 2017;41:111-24.

35. Ahima RS, Park HK. Connecting Myokines and Metabolism. Endocrinol Metab (Seoul) 2015;30:235-45.

36. Argilés JM, Busquets S, López-Soriano FJ, et al. Are there any benefits of exercise training in cancer cachexia? J Cachexia Sarcopenia Muscle 2012;3:73-6.

37. Di Girolamo FG, Situlin R, Mazzucco S, et al. Omega-3 fatty acids and protein metabolism: enhancement of anabolic interventions for sarcopenia. Curr Opin Clin Nutr Metab Care 2014;17:145-50.

38. Dallmann R, Weyermann P, Anklin C, et al. The orally active melanocortin-4 receptor antagonist BL-6020/979: a promising candidate for the treatment of cancer cachexia. J
Cachexia Sarcopenia Muscle 2011;2:163-74.

39. Grossmann M. Myostatin inhibition: a new treatment for androgen deprivation-induced sarcopenia? J Clin Endocrinol Metab 2014;99:3625-8.

40. Berardi E, Annibali D, Cassano M, et al. Molecular and cell-based therapies for muscle degenerations: a road under construction. Front Physiol 2014;5:119.

41. Kung T, Springer J, Doehner W, et al. Novel treatment approaches to cachexia and sarcopenia: highlights from the 5 th Cachexia Conference. Expert Opin Investig Drugs 2010;19:579-85.

42. Garaci E. From thymus to cystic fibrosis: the amazing life of thymosin alpha 1. Expert Opin Biol Ther 2018;18:9-11.

(English Language Editor: L. Huleatt)

Cite this article as: Wang Y, Chen $\mathrm{P}$, Huang J, Liu M, Peng D, Li Z, Chen T, Hong S, Zhou Y. Assessment of sarcopenia as a predictor of poor overall survival for advanced non-small-cell lung cancer patients receiving salvage antiPD-1 immunotherapy. Ann Transl Med 2021;9(24):1801. doi: 10.21037/atm-21-6578 